\title{
«Lo que me embarga el ánimo»: Miguel de Unamuno y la Gran Guerra
}

\section{Università per Stranieri di Perugia}

\section{Fecha recepción 20.10.2014 / Fecha aceptación 06.04.2015}

\section{Resumen:}

Doña Emilia Pardo Bazán decía que lo mejor de Miguel de Unamuno eran sus epistolarios - su «epistolomanía», como él mismo la definía - en los que no sólo encontramos las claves para el estudio de su vida y de su obra, sino, sobre todo, a ese hombre que, de manera espontánea, con la emoción de lo inmediato, nos cuenta su pensamiento, y su época. Y ese es, del mismo modo, el Unamuno que escribe a su amigo francés Jacques Chevalier el 22 de diciembre de 1914, es decir, un Unamuno que, cinco meses después del estallido de la guerra, entrega a su pluma sus sentimientos, sus preocupaciones sobre la dramática situación que estaba viviendo Europa en aquel momento.

\section{Palabras clave}

Guerra, neutralidad, intelectuales, cartas, identidad

\section{Abstract}

Doña Emilia Pardo Bazán said that Miguel de Unamuno's best aspects were his epistolary works and his "episto-mania", as he defined it, in which there is not only the keys to the study of his life and works, but also a man who in a spontaneous way, and with an immediate emotion, tells us about his thoughts and his time. In this vein, Unamuno writes to his French friend Jacques Chevalier on the 22 December 1914. These are the words of a man who, five months after the outbreak of war, entrusts his pen with his feelings, his worries for the dramatic situation that Europe was living in that moment.

\section{Key words}

War, neutrality, intellectuals, letters, identity 
Para intentar reflexionar sobre la dimensión «española» de la Gran Guerra, de la guerra, es decir, en la que España no quiso participar, pero que, como nos recuerda E. Pérez Aunós, de alguna forma «se le metió en casa» ${ }^{1}$, voy a inspirarme en una carta que Miguel de Unamuno escribió a su amigo Jacques Chevalier el 22 de diciembre de 1914. Doña Emilia Pardo Bazán decía que lo mejor de Miguel de Unamuno eran sus epistolarios -su «epistolomanía», como él mismo la definía- en los que no sólo encontramos las claves para el estudio de su vida y de su obra, ya que nos permiten también, y sobre todo, enfrentanos con el «Unamuno vivo, real y de carne y hueso» ${ }^{2}$, con aquel hombre que de manera espontánea, con la emoción de lo inmediato, nos cuenta su pensamiento, su época ${ }^{3}$. Y ese es, del mismo modo, el Unamuno que escribe a su amigo francés, un Unamuno que cinco meses después del estallido de la guerra entrega a su pluma sus sentimientos, sus preocupaciones sobre la dramática situación que estaba viviendo Europa en aquel momento:

«Lo que me embarga el ánimo es la guerra, la gran guerra, la lucha de la democracia, de la justicia contra el imperio de la fuerza, contra esa bárbara Kultur -K mayúscula, rectilínea, de cuatro picos, a modo de caballo de frisa-, del águila cacareadora $»^{4}$ : las palabras a las que recurre en estas pocas líneas son, en mi opinión, el reflejo más nítido del desgarro íntimo que sufría Unamuno con respecto a la guerra, y también trazan el camino que nos lleva a reflexionar sobre el papel que tuvieron los intelectuales españoles, testigos de una neutralidad, $o$ de lo que, quizás, se podría definir «una guerra no declarada» ${ }^{5}$.

1. E. Pérez Aunós, Itinerario de la España contemporánea, Barcelona, 1940, 326.

2. L. Robles, "Introducción" en M. de Unamuno, Epistolario inédito (1894-1914), I, Madrid, 1991, 22.

3. La importancia de los epistolarios para recomponer el pensamiento y la vida de los intelectuales españoles del siglo XX resulta también evidente en la biografía reciente de Jordi Gracia sobre Ortega y Gasset, donde el autor ha intentado «humanizar a un escritor inhumano: excepcional por talento, valentía e inteligencia, también suspicaz y altivo como pocos. [...] Debía ser Ortega quien se contase y yo quien decidiese qué contaba él, a la luz de sus textos públicos y privados, los editados y los inéditos, y desde luego a la vista de un epistolario riquísimo y en su mayor parte inédito, además de las cartas y testimonios de los demás cuando se ocupan de Ortega, sobre todo si esos otros se llaman Juan Ramón, Antonio Machado, Baroja, María de Maeztu, Azorín, Azaña o Zambrano». Véase J. Gracia, José Ortega y Gasset, Madrid, 2014. 4. de Unamuno, Epistolario inédito... op. cit., 356.

5. Cuando hablamos de «guerra no declarada» nos referimos a lo que subrayan los historiadores Eduardo González Calleja y Paul Aubert en su recién trabajo, al afirmar que «el conflicto no se detuvo a las puertas 
«La situación económica, la debilidad militar, la indecisión de un monarca dividido entre una madre austriaca y una esposa inglesa, entre su gusto por los desfiles del ejército prusiano y sus amistades francesas, el hecho de que ninguna razón vital obligaba a entrar en la guerra [...] todo concurrió para hacer de España un país neutral» ${ }^{6}$, nos recuerdan E. González Calleja y P. Aubert, subrayando algunas de las razones que han hecho de España más un sujeto pasivo que un actor en el escenario internacional de los últimos dos siglos. De hecho, la historia contemporánea de España ha sido caracterizada y afectada por un largo aislamiento que, desde el principio, ha representado una de las causas, quizás la más determinante, de la inquietud que ha sufrido el país durante esta época. En efecto, con el comienzo en 1810 del proceso de independencia de las colonias americanas, y el consiguiente desmoronamiento del Imperio, España se iba enfrentando cada día más con la debilidad, con la inadecuación de su política exterior, y con la fragilidad de su política interior, espejo de un sistema que no lograba garantizar equilibrio y estabilidad a una tierra que se encaminaba hacia uno de los momentos más oscuros de su historia. Esta es la perspectiva desde la que se tienen que analizar los debates sobre la neutralidad española durante la Primera Guerra Mundial, ya que, según muchos políticos e intelectuales de la época, la participación en la Gran Guerra hubiera podido representar una importante oportunidad para devolver a España un papel digno a nivel internacional. El Conde de Romanones, en su prólogo a la obra de Albert Mousset La política exterior de España (1873-1918), afirma que «el no haber dado España en todo momento preferente valor y atención a su política exterior es una de las principales causas de nuestra decadencia» ${ }^{7}$, y añade que

«en España ha faltado en los directores de su vida pública afición para los problemas de política exterior, deseo de conocer lo que ocurre al otro lado de nuestras fronteras. La opinión nunca se ha interesado tampoco en examinar la conveniencia de entablar vínculos con unas $\mathrm{u}$ otras naciones, unas veces por amor propio excesivo y otras tomando como fundamento una debilidad y pequeñez que existe más en nuestro proprio ánimo que en los ajenos [...]. Las Naciones que no quieren perder su categoría y rango son aquellas que más obligadas están a seguir con afán constante todo cuanto ocurre en el mundo, a procurar que no se prescinda de ellas en ningún momento» ${ }^{8}$.

de España, sino que penetró profundamente en el tejido social, político, económico y cultural del país [...]. La imagen de la beatífica neutralidad española resulta, pues, falsa. El país contempló la alteración de todas las facetas de su vida colectiva, y vio amenazada su soberanía, base de su neutralidad, en aspecto tan vitales como la libertad de comercio, la autonomía política de sus gobiernos, la intangibilidad de sus archipiélagos, la integridad de sus costas, la soberanía de sus aguas, la seguridad de sus intereses materiales o la neutralidad de su Administración»; E. González Calleja y P. Aubert, Nidos de Espías. España, Francia y la Primera Guerra Mundial 1914-1918, Madrid, 2014, 28.

6. González Calleja y Aubert, op.cit., 22.

7. Conde de Romanones, "Prólogo" en A. Mousset, La política exterior de España (1873-1918), Madrid, 1918,10 .

8. Conde de Romanones, op. cit., 10. 
En este último párrafo Romanones subraya lo que hacen las naciones para no perder su «rango internacional» y lo que, por entonces, hubiera tenido que hacer España; sin embargo, en mi opinión, el país que salía del 98 y de todo lo que el desastre significó, no podía, ni probablemente sabía ponerse a la «altura» internacional de las demás naciones europeas, ya que ni siquiera había conseguido identificarse en el concepto de nación ${ }^{9}$. De hecho, la derrota de la marina española en la guerra hispano-cubana no significó sólo la desaparición definitiva de la palabra «imperio» de las páginas de los libros de historia, sino, sobre todo, la dificultad de sustituir este término con algo con lo que los españoles se identificasen: lo que quedaba del glorioso imperio era un territorio claramente delimitado geográficamente dentro de los confines europeos, al que no correspondía una igualmente bien delimitada conciencia nacional: empieza, de este modo, esa espasmódica búsqueda de una nueva identidad que constituirá el fundamento de la vida de España y de los españoles durante todo el siglo $\mathrm{XX}^{10}$. Y de este clima de confusión, de inquietud, es de donde tenemos que empezar para intentar comprender cómo se colocan los intelectuales españoles en la Gran Guerra, puesto que sus plumas se convirtieron en las trincheras que marcaban el confín entre aliados e imperios centrales, con la angustiada esperanza de encontrar en la lucha entre "germanofilia» $\mathrm{y}$ «aliadofilia» también las respuestas y, quizás, las soluciones, a lo que Mallada definía «los males de la patria» ${ }^{11}$.

Como ya hemos recordado, con la declaración de guerra a Francia por parte de Alemania, España se apresuró a proclamar su neutralidad el 7 de agosto de 1914, posición que el gobierno de Eduardo Dato consideraba la única opción posible, calificando de "política de aventura» cualquier intervención bélica y explicando que «sólo en el caso de verse en peligro la independencia de la nación, la integridad del territorio o el honor de España» ${ }^{12}$ el país se lanzaría a la guerra:

9. De todos los vocablos que caracterizan el lenguaje de la política, quizá sea «nación» uno de los más problemáticos, especialmente controvertido y debatido, sobre todo, en la actualidad, después de la vuelta a la escena política de formas agresivas de nacionalismo. El concepto ha sido objeto de interpretaciones opuestas: ¿ las naciones nacen de un patrimonio de historias y culturas compartidas o más bien, son fruto de una «invención» en respuesta a exigencias políticas específicas? De ahí, la imposibilidad de observar el desarrollo de la nación española del siglo XX sin ponerla en relación con algunos pasos claves de la historia del pensamiento político europeo, desde el nacimiento del estado moderno hasta la edad de la globalización, pasando por la Revolución francesa, el liberalismo del siglo XIX y la época de los nacionalismos. Con respecto a la evolución del concepto de nación véase, entre otros, A. Campi, Nazione, Bolonia, 2004.

10. A pesar de la crisis social y política que estaba sufriendo España en el periodo bélico, no deberíamos olvidar que estos años coinciden con el apogeo cultural y científico de la llamada generación del' 14 , sin duda la más europeísta de la historia de la Península en el siglo XX. Sobre el argumento véanse: M. Menéndez Alzamora, La generación del 14. Una aventura intelectual, Madrid, 2006; F. José Martín (ed.), Intelectuales y reformistas. La Generación de 1914 en España y América, Madrid, 2014.

11. Véase L. Mallada, Los males de la patria y la futura revolución española, Madrid, 1969.

12. N. Aguirre de Carcer (ed.), "Declaraciones oficiales españolas -Real Orden, 7 de Noviembre de 1914", La neutralidad de España durante la Primera Guerra Mundial (1914-1918), Madrid, 1995, 4. 
«Si ese caso llegase, señores, nosotros somos españoles y nosotros sabemos responder a la tradición gloriosa de la noble y vieja España, sacrificando nuestras vidas, que nada valen, por la integridad y la independencia de nuestro territorio. Entre tanto, y mientras llega la hora de la paz, ansiada por la humanidad entera con angustia infinita, mientras esa hora bendita llega [...], nosotros debemos cumplir austeramente con los estrechos deberes que la neutralidad impone, no sólo deberes oficiales y deberes del Parlamento, sino deberes de toda la nación española, de respeto, de admiración, de conmiseración a aquellos pueblos que sufren los horrores de la guerra, deberes que responden a la tradicional hidalguía del pueblo español $»^{13}$.

Así que España, una vez más, se colocaba en una soledad diplomática que Ortega consideraba quizás inevitable, pero sin duda doliente:

«Nosotros no podemos mirar a los últimos sesenta años de nuestra vida sin sonrojo y sin ira. Los directores de nuestra patria han hecho de ella lo contrario de lo que hicieron con la suya los directores de la raza italiana: éstos han hecho a Italia, aquellos han deshecho a España. Y hoy cuando llega la hora, ya inminente, de entrar Italia en la guerra absoluta, en la guerra definitiva, vamos a sentir con evidencia aterradora que somos una nación descaminada. Y cuando la base entera del Mediterráneo haya entrado en la liza, ¿qué sentiremos los españoles? ¿Cómo interpretaremos la emoción de soledad que ha de sobrecogernos? La cómoda, grata, dulce, neutralidad ¿seguirá pareciéndonos la mejor de las políticas? ¿Nos parecerá siquiera una política?» ${ }^{14}$.

La «cómoda, grata, dulce, neutralidad» orteguiana se iba a sumar a las llamadas " "neutralidad vigilante" en tiempos de O’Donnell, "aislamiento" con Cánovas, "recogimiento" con Moret» ${ }^{15}$, es decir, reiteraba la exclusión de España del concierto de las naciones mediterráneas y, por consiguiente, subrayaba, según los intelectuales y políticos españoles que no eran partidarios de la neutralidad, la inferioridad del país. «Eran conscientes de que esa guerra no era una guerra cualquiera, y que la victoria de uno u otro campo marcaría el futuro de Europa $»^{16}$, y por esto no entendían que se pudiera aspirar a la felicidad mediante una neutralidad pasiva, frente a lo que Pérez de Ayala llamaba «la guerra del mundo, guerra de

13. Aguirre de Carcer, loc.cit., 4-5.

14. J. Ortega y Gasset, "Política de la neutralidad, La camisa roja", España. Semanario de la vida nacional, 29 de enero, 1915, 2. Las palabras de Ortega aparecieron en el primer número de la revista España, es decir, «meses después de haber comenzado la guerra, pero justo a tiempo de dejarnos un valioso testimonio contemporáneo por medio de las letras y las ilustraciones, acerca de su visión del conflicto». De hecho, el semanario, fundado por Ortega como un órgano más de su Liga de Educación Política, nació con el objetivo de fomentar y extender las ideas de toda una generación de intelectuales que «intuyen un nuevo orden europeo, y ven necesario que España se una a Europa en el proceso de modernización y reforma que saldrá de la guerra. Respecto a esta integración de España en Europa, para Ortega y Gasset no se puede dejar pasar la oportunidad de participar en una guerra en la que incluso Italia va a entrar». Véase P. Ramírez Benito, "La Gran Guerra vista desde la intelectualidad de la revista España. Semanario de la vida nacional (1915-1924)", Sucesos, guerras, atentados. La escritura de la violencia y sus representaciones, Paris, 2009, 57-82.

15. González Calleja y Aubert, op.cit., 24.

16. González Calleja y Aubert, op.cit., 24. 
civilización $»^{17}$. «La guerra era percibida como un acontecimiento que abría muchas posibilidades, empezando, más allá de la lucha entre culturas y morales, por una pelea entre "la España oficial y la España vital" ${ }^{18}$, y es en este contexto, es decir, en una guerra entre aliados e Imperio Central percibida por algunos como una batalla entre democracia y autocracia, donde encontramos a intelectuales como Miguel de Unamuno que, dirigiéndose a su amigo Chevalier, afirma que en España:

«todos los enemigos de la democracia, de la libertad, de la opinión libre, todos los inquisitoriales que desgraciadamente son muchos, abogan por Alemania. Se une el tradicional recelo al vecino, a Francia, y una ojeriza grande a Inglaterra, y no sólo por lo de Gibraltar. Aquí se cree y se dice que en Francia e Inglaterra se nos desdeña y se nos desprecia. Y yo digo que en Alemania ni se nos conoce. Porque no es conocer el que un erudito estudie a unos de nuestros clásicos del siglo XVII. Para los alemanes no existimos» ${ }^{19}$.

Las palabras de Don Miguel se sitúan en aquella «guerra civil» presente en España entre los germanófilos y los aliadófilos, entre las derechas y las izquierdas, entre los que interpretaban el mantenimiento de la neutralidad como la renuncia a aprovechar la última oportunidad para que España restableciese su prestigio internacional tras el desastre de 1898 y los que se alegraban de haber evitado una peligrosa aventura. Sobre todo, son palabras que dejan transparentar la amargura, el resentimiento hacia el enemigo interior, esto es, aquel «germanófilo español» que los miembros de la Liga Antigermanófila ${ }^{20}$ consideraban partidarios de la tradición reaccionaria y hostiles a la herencia ideológica de la Revolución francesa y a los ideales laicos y republicanos. Lo que escribe Unamuno a Chevalier, en efecto, nos guía por un camino que parte de un contexto internacional para llegar a un doloroso debate en torno a la política interior y a la esencia del régimen español o, mejor dicho, de un sistema que llevaba en sí mismo todos los fracasos de una Restauración heredera, entre otras cosas, del aislamiento internacional conscientemente construido por Cánovas ${ }^{21}$. En fin, en la carta

17. R. Pérez de Ayala, "Política y toros", Obras Completas, III, Madrid, 1963, 832.

18. González Calleja y Aubert, op.cit., 22.

19. de Unamuno, Epistolario inédito... op. cit., 358.

20. Según avanza la guerra, el 18 de enero de 1917, se publica en España el Manifiesto de la Liga Antigermanófila, según el cual, los «antigermanófilos» no se declaran «germanófobos» pero sí contrarios a la política alemana:

«La Liga Antigermanófila no es germanófoba. Admira en Alemania lo que en ella hay de grande y permanente y repudia en ella lo que pugna con el espíritu libertador de la Historia. No simpatiza con el Estado alemán porque representa la negación de las pequeñas nacionalidades en su política exterior, y de la democracia, y en general del espíritu civil, en la interior»; España, 18 de enero de 1917. Véase P. Ortiz de Urbina, "La Primera Guerra Mundial y sus consecuencias: la imagen de Alemania en España a partir de 1914", Revista de Filología Alemana, 15, Madrid, 2007, 193-206.

21. Sobre el papel que tuvo Cánovas en la política exterior española de la segunda mitad del siglo XIX, véase, entre muchos otros, G. Scocozza, España en los comienzo de la edad contemporánea. Cánovas y la cuestión cubana, Bogotá, 2012. 
enviada al amigo francés, es posible reconocer al intelectual que toma parte «activa» en la política del momento, que firma manifiestos, que asiste a mítines, es decir, según afirma Espada Burgos, «es precisamente en esa polémica originada por la guerra cuando se puede situar en España la presencia del intelectual comprometido y de una manera corporativa tanto como actor (firmante de manifiestos) como en su condición de testigo o de conciencia crítica de un momento de su país» ${ }^{22}$.

La correspondencia entre Unamuno y Chevalier, sin embargo, nos ofrece mucho más que la figura de un intelectual comprometido e indignado. Las palabras, las líneas, las emociones a través de las que la carta toma vida recogen, en mi opinión, algo sobre lo que merece la pena centrarse: las reflexiones de Don Miguel parecen atravesar el concepto de neutralidad para luego dividirse en dos momentos que acabarán por encontrarse y afectarse el uno al otro. El hecho de analizar la Gran Guerra a partir de esta carta, sin duda, nace porque entre las líneas de este escrito se percibe la posibilidad de llegar a la guerra a través del hombre y su tierra, más que a través del intelectual y sus novelas: es decir, en las páginas dirigidas a Chevalier el Umanumo intelectual se manifiesta, sobre todo, como el hombre hijo de su época, afligido por el futuro de su pueblo y, al mismo tiempo, testigo y víctima de las contradicciones de su país. En la carta, indudablemente, ya desde las primeras líneas podemos destacar como la «dimensión» nacional e internacional de las reflexiones a las que se abandona Don Miguel coincide con una dimensión personal de particular relevancia:

«Hace tiempo, mi muy querido amigo, que deseaba escribirle. Pero he andado en un trajín muy grande. No quiero entretenerle con lo de mi destitución. Ha sido una pequeña miseria de nuestra politiquilla interior. Y precisamente por no ser yo político de partido, que ése es mi pecado. Pero con ello he ganado en prestigio. Mi último viaje a Madrid, hace quince días, a iniciar una campaña contra la beocia que nos desgobierna fue un éxito enorme. Jamás me he visto mas aclamado. Todo ello me ha servido para medir mi fuerza, que es mayor que creía» ${ }^{23}$.

Como puede intuirse, la carta esta escrita en unos de los momentos más difíciles de la vida del intelectual vasco, es decir, en los meses inmediatamente posteriores a su destitución como Rector de la Universidad de Salamanca. El 31 de agosto de 1914, efectivamente, como nos recuerda Emilio Salcedo:

«en la Plaza Mayor cuelgan los periódicos locales unas carteleras en que dan avances de las noticias mas salientes que van a publicar. Los titulares de la guerra europea llenan las planas de todos los diarios y la gente tiene avidez de noticias. Entre los telegramas de guerra, la agencia de información lanza una bomba auténtica: Bergamín ha destituido al rector. Y Unamuno se entera bajo los portales de la Plaza Mayor de Salamanca, en la cartelera de un periódico» ${ }^{24}$.

22. M. Espada Burgos, "De la época bismarckiana a la Gran Guerra”, en W. Bernecker, España y Alemania en la Edad Contemporánea, Fráncfort, 1992, 79.

23. de Unamuno, Epistolario inédito... op. cit., 356.

24. E. Salcedo, Vida de Don Miguel, Salamanca, 1964, 185. Para una visión amplia y detallada de la vida de Unamuno, cuyas vivencias y acciones estuvieron estrechamente vinculadas a la vida política y cultural de 
La destitución, como sabemos, fue un trago difícil, sobre todo, por el modo en el que el ex-rector se enteró de la noticia, ya que, como el mismo afirmó, «no precedió a ella [la destitución] ni aviso ni amonestación, ni queja alguna de mi conducta como rector o particular; es decir, que no se me ha guardado absolutamente ninguna consideración personal» ${ }^{25}$. Las causas que indujeron al entonces Ministro de Instrucción publica, Bergamín, a destituir del Rectorado a Unamuno no resultaron, ni resultan, claras, ya que, presumiblemente, «hay que sumar muchos datos: la filiación socialista de Unamuno, [...]; sus campañas agrarias [...]; el incidente del estudiante colombiano; la lucha del rector por la libertad de cátedra [...]; su difícil posición religiosa ${ }^{26}$. Sin embargo, si por un lado la destitución sigue siendo un capítulo no muy claro tanto de la historia personal de Don Miguel como de la universidad española, por el otro absolutamente claras y definidas fueron las reacciones que produjo. Muchísimos intelectuales enviaron cartas a Unamuno en las que expresaban su solidaridad por todo lo ocurrido; entre ellos, Luis de Zulueta, Manuel García Morente, Francisco Giner de los Ríos u Ortega y Gasset, quien desde el primer momento le dijo que podía contar incondicionalmente con él y su «mal genio», de la misma manera en la que Ramiro de Maeztu, algunos días después, puso su pluma a sus órdenes, por si en algo podía contribuir a reparar la dignidad herida de Don Miguel. Y fueron precisamente estos amigos y admiradores los que, por mano de Salvador de Madariaga, pidieron al ex rector «que su próxima venida a Madrid sea una manifestación digna y fuerte de protesta contra el atropello de que ha sido usted victima ${ }^{27}$; solicitud que se concreta el 25 de noviembre de 1914 con una conferencia en el Ateneo de Madrid titulada Lo que ha de ser un rector en España:

«De la universidad española actual no cabe decir que es una ruina, porque no existe. Esas miserables fábricas de licenciados y colegios electorales no merecen semejante nombre. [...] Y si queremos levantar la vista de la triste miserias que os he mostrado, $\iota^{a}$ dónde hemos de alzarla sino a esa guerra noblemente trágica, solemnemente transcendental, que hoy arde ante el altar de la cultura en lo más íntimo de Europa? Ella ha servido para que se trame aquí una tregua política [...] pero ella traerá, estad seguros, una sacudida espiritual, no sólo a los pueblos beligerantes, sino a los al parecer neutros, a nuestra pobre España entre ellos ${ }^{28}$.

Las afirmaciones, las quejas que Unamuno expuso con fuerza y rabia durante su conferencia, resonaron más bien como una «acusación clara y decidida contra un sistema: tiene presente lo que ha sido su lucha en la Universidad de Salamanca, y siente el desfallecimiento de la hora mala en que toda esperanza se pierde y sólo queda el grito, el derecho al pataleo» ${ }^{29}$.

España durante más de cinco décadas, véase también el reciente estudio de Colette y J.-C. Rabaté, Miguel de Unamuno. Biografía, Madrid, 2009.

25. Salcedo, op. cit., 185.

26. Salcedo, op. cit., 188.

27. Salcedo, op. cit., 189.

28. M. de Unamuno, “Lo que ha de ser un rector en España’: conferencia leída en el Ateneo de Madrid el día 25 de noviembre de 1914"; Nuevo Mundo, Madrid, 1914.

29. Salcedo, op. cit., 194. 
Las palabras de Salcedo nos llevan al momento en el que la vida de un hombre se encuentra, para confundirse, con la vida de su gente y de su tierra. Y es este el hombre que escribe a Chevalier, es decir, un Unamuno víctima de un sistema enfermo y corrupto pero, al mismo tiempo, con la necesidad de rescatar a su pueblo; que no quiere centrarse en «la pequeña miseria» de la «politiquilla interior» de España y que, al mismo tiempo, busca consuelo en la aclamación de Madrid.

El dolor y la esperanza del hombre, por lo tanto, se unen y se identifican con el dolor y la esperanza de su época: «Y vea usted como veo yo en esta guerra una guerra de cultura. El actual Imperio Germánico, anti-democrático y corruptor, es algo tan terrible como fue el imperio napoleónico francés de 1870. Y tienen que vencer los pueblos contra el puro Estado, el Estado sin pueblo. Y será ello la liberación de los alemanes» ${ }^{30}$. Estas son las palabras con las que Unamuno expresa a su querido amigo francés lo que piensa de la guerra, en una correspondencia que enfrenta no sólo a dos intelectuales, sino, sobre todo, a dos hombres que viven y sienten la guerra con la misma alma, como subraya Chevalier en la carta del 11 de octubre de 1914 cuando, dirigiéndose a Unamuno, afirma:

«[..] voilà aussi pourquoi, cher ami, il serait si important pour l'avenir du monde que les neutres, que votre chère, noble et pure Espagne, se déclarent: leur intervention aurait une portée morale immense, précisèment parce qu' ils n'ont pas d'intérêt direct, immédiat, personnel dans la lutte, et qu'ainsi leur voix s'éleverait comme la voix de la justice et de la conscience humaines. Vous le savez, vous le sentez, comme nous mêmes $[\ldots ..] »^{31}$.

Y a este «sentir» se dirige el profesor francés cuando escribe a su amigo español, para que pueda convencer a su gente y a su gobierno a abandonar una neutralidad demasiado peligrosa: "c'est une question de vie et de mort pour nous, et, j'ajoute, pour l'humanité, pour la civilisation toute entière» ${ }^{32}$. Sin embargo, es precisamente este «sentir», o, mejor dicho, este «vosotros sentís», el que marca la distancia entre los dos intelectuales en el pasaje de hombre a pueblo, de ciudadano a nación. ¿A quién esta solicitando ayuda y alianza el Chevalier hijo de su Francia? ¿En qué «vosotros» se convierte el «vous» del francés? O mejor, ¿a qué España se está pidiendo que participe en la guerra al lado de los aliados? Así llegamos al momento en el que, en mi opinión, la neutralidad española se presenta como sinónimo de esa ausencia de identidad nacional que hizo casi necesario o inevitable permanecer en el «limbo». Después del 98, de hecho, la búsqueda del nuevo «ser» de España continuaba siendo el problema principal del país, problema que se inscribía en un inexistente diálogo con una Europa todavía demasiado lejana.

Aquí se halla el afán por definir a España a través de Europa, o de individuar una Europa española, pero, sobre todo, la necesidad perenne de encontrar una España en la que

30. de Unamuno, Epistolario inédito... op. cit., 358.

31. M. García Blanco, "Unamuno y el profesor francés Jacques Chevalier", Estudios sobre Unamuno. Revista de la Universidad de Madrid, 13, 49-50, Madrid, 1964, 33-34.

32. García Blanco, op.cit., 33. 
todos los españoles se reconociesen como hijos de una misma y unida nación. Este es el país que busca Unamuno, el país del que quiere hacerse portavoz y que, en su opinión, tendría el deber de defender la causa de los aliados. Pero este país todavía no existe: España era en aquel momento una nación in fieri, perdida en los meandros de su identidad, sin haber individuado todavía la salida del laberinto. $Y$ en este contexto se coloca el Unamuno al que se dirige Chevalier, aquel hombre que el filósofo francés, en un escrito titulado Hommage à Unamuno, define orgullo de España y de la humanidad entera, capaz de ser universal y, al mismo tiempo, de no dejar nunca de ser español y que, precisamente con el apego a su tierra, ha fundado su humanismo:

«Miguel de Unamuno, recteur de l'Université de Salamanque, est, à l'heure actuelle, le plus éminent représentant des lettres et de la pensée espagnoles, et l'un des hommes qui sont l'honneur de leur pays aussi bien que de l'humanité. Pour être, comme il l'est, profondément, typiquement et universellement homme, il n'a pas eu à cesser d'être Espagnol: c'est au contraire dans son fervent attachement à sa terre, à sa race et à son peuple, que Don Miguel, ainsi que le dénomment familièrement ses compatriotes, a puisé le suc de son humanisme; et c'est parce qu' il est lui-même, c'est parce qu'il est, suivant l'une de ses expressions favorites, "Un homme en chair et en os", que tous se reconnaissent en lui et qu' il appartient en quelque manière à tous, s'il est vrai, comme il l'a dit, que le véritable universel c'est le singulier ${ }^{33}$.

Y éste es el Unamuno sobre el que hemos querido reflexionar: el intelectual, el hombre, el español que mira hacia la guerra desde una perspectiva que quizás hubiera podido ser fuente de inspiración para Anderson, algunos años más tarde, en su definición de Imagined Communities, es decir, un Unamuno que quiere y necesita llegar a la afirmación de una nación española como consecuencia de un proceso fundado en la tradición, y orientado hacia la creación de un imaginario común, para alcanzar un horizonte de memorias colectivamente compartidas llamado España ${ }^{34}$.

33. Véase J. Chevalier, "Hommage a Unamuno", Cuadernos de la Cátedra Miguel De Unamuno, 1, Salamanca, 1948, 9-28.

34. Véase B. Anderson, Imagined Communities: reflections on the origin and spread of nationalism, New York, 2006. 